
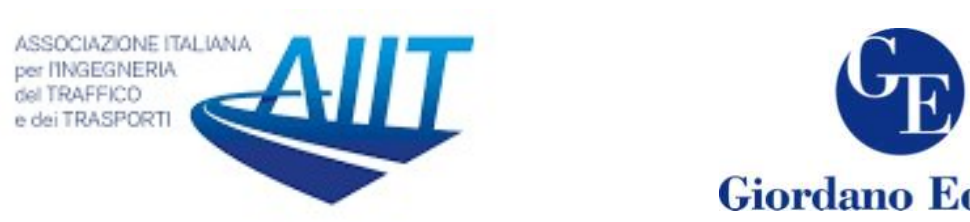

Giordano Editore

\title{
A strategy of quick hierarchization of road bridge maintenance activities
}

\author{
Giovanni Andriulo ${ }^{1}$, Francesco Freddi ${ }^{1 *}$, Pietro Mattina ${ }^{1}$ \\ ${ }^{I}$ Department of Engineering and Architecture, Università di Parma, Parco Area delle Scienze 181 / A, \\ I 43124 Parma, Italy
}

\begin{abstract}
The control and maintenance of infrastructures is a crucial aspect for the sustainability and development of the economic and social activities of a country. The managing authorities, in order to preserve the efficiency and safety of the traffic flows, have to deal with a rather old infrastructure asset that is often in a non-optimal conservation state with an increasing degradation process induced by the increment of the traffic loads and by the environmental actions. The situation is exacerbated by the limited economic resources and reduced workforces at disposal with the consequence that an order of priority in the maintenance plain is anavoidable. This work provides a logical tool to define the hierarchy of the maintenance plain of the infrastructural heritage based on one hand on the structure state of conservation and on the other hand on the context in which the construction is integrated
\end{abstract}

Keywords: Bridges, viaducts, decay, road maintenance, highway management.

\section{Introduction}

The Bridge Management Systems (BMS) are decision support tools that the road infrastructure managing authorities employ to census the structures and collect the conservation information obtained through inspection and monitoring activities. These systems are aimed at achieving rational maintenance plan, conservation and structural improvement interventions by optimizing the technical and managerial processes, setting aside the necessary economic resources (Ryall, 2001, Godart et al., 2001).

The information that structures the BMS are complex and heterogeneous, not only based on data necessary for predictive degradation models - consequence of the different deterioration mechanisms - but also on aspects that correlate the importance of bridge efficiency with the concept of structure integrity risk. The main goal of the BMS is the definition of the best maintenance intervention timing with the control of the degradation levels. The latter have always to be kept below the user's sensitivity and, obviously, of intrinsic safety.

\footnotetext{
${ }^{*}$ Corresponding author: Francesco Freddi (francesco.freddi@unipr.it )
} 
Historically, the BMS arise and develop with the evolution of the concept of structure durability, deeper knowledge and awareness on material degradation and aging related to time factors, class exposure and characteristics of the exercise.

The technical literature has often anticipated valid scientific approaches that in recent years have improved the logic of BMS to levels of considerable importance and sophistication (Ryall, 2001).

Among the international management experiences, BMS have been developed and enhanced in various countries with apparently similar methodologies. Actually, they have been adapted each time to the needs of the managing authorities and to the typological complexity of the infrastructure heritage. Examples of BMS are the US PONTIS system of the Federal Highway Administration (FHWA, 1991), the Japanese J-BMS (Miyamoto and Motoshita, 2015). European contributions are very significant both in the national systems (Scutaru et al., 2018), both in initiatives aimed at harmonizing Bridge Management in Europe (BRIME, 2002).

The differentiation of the BMS at a national level finds technical and political justification due to the extreme diversification of the authorities responsible for managing the infrastructural heritage. States and regions are called to manage bridges of different eras, of typological variety both in the static scheme and materials, and construction techniques referable up to about 150 years.

BMS in Italy has its peculiar characteristics representing a challenge and an experiential basis useful for international researchers, specifically for what concerns the management of the heritage of the suburban roads of the main, secondary and local roads.

The administrative decentralization of road management in favour of 107 provinces, transfers to technical departments the responsibility of implementing a bridge management system that has to be open to system customization, with fast and easy to execute strategies. In this regard, the "Linee guida per la classificazione e gestione del rischio, la valutazione della sicurezza ed il monitoraggio dei ponti esistenti", which are currently being tested under the guidance of the Consiglio Superiore dei Lavori Pubblici, provide the basis for a more conscious and fully automated management of the huge infrastructure assets spread throughout the Italian territory.

The current historical era witnesses in Italy the achievement of a stabilization on the apical values of the motorisation rate (Garilli et al., 2017) and, as in Europe, a late critical evaluation of the management of exceptional mass and size transits (Autelitano et al., 2017) which lead to drastic reconsiderations of the estimates of the useful life of roads and, above all, of bridges.

On the other hand, in Italy, as in many European countries, the coexistence of different types of bridges is very frequent and numerous are the reinforced concrete structures built in epochs where the rigour of structural calculation was often predominant compared to a full conscience of durability (Kun et al., 2015; Calvi et al., 2019).

In this perspective, while bearing in mind the considerable strategic system investments, in this work a BMS structured by logical flow and composition of single split operations has been developed, in order to achieve a hierarchy of the status indicators of the structures, which can be implemented at the level of the single administrative entity.

The logical flow chart of the proposed management system is finalized to the optimization of resources through a rapid hierarchy of infrastructures to be maintained with interventions modulated according not only to the state of the structures but also to the resilience of the road network, the compatibility of the construction with the traffic requirements of the artery in which it is included. 


\section{Structure of the method}

The initial phase of a BMS is the cataloguing process: a systematic collection of a series of basic information for the identification of the bridge, such as the name, the street in which it is inserted, the progressive mileage and the geographical coordinates (latitude and longitude) needed to locate the structure.

This phase is by far not trivial, since much of the managed assets are missing the original projects (certainly for all the historical viability) nor equipped with a computerized register (road cadastre, signpost cadastre, services cadastre) and implies complex archive searches.

Subsequently, the phase of completion of the geometric and functional information takes place. Here, the static scheme and the role of the main structural components that will be ritually subjected to visual inspection are determined.

The acquired data, eventually with several inspections, will be compared with typological reference databases and will have to ensure the minimum knowledge requirements to be achieved (MR).

The information that converge in a database must be suitable for the quantification of a synthetic indicator, named Relative Risk Index ( $\left.\mathrm{IR}_{\mathrm{R}}\right)$, of the real state of conservation of the structure. A further cognitive step, considers the bridge within a more complex reading by evaluating its importance throughout the road network by calculating an Absolute Risk Index $\left(\mathrm{IR}_{\mathrm{A}}\right)$.

The construction of a hierarchy of risk levels and of the consequent maintenance and / or reconstructive intervention priorities can be explicated through critical ranges which presupposed, consequently, also a specialized frequency of the future inspections and the bridge monitoring strategies. The entire process is summarized in the flowchart of Fig. 1.

\subsection{Database construction: census and inspection process}

The construction of the Database should be arranged not only for entries but also on the ease of compilation by technicians with different levels of qualification, on the use of codified procedures for the recognition of essential geometric characteristics, for the identification of deteriorations according to a comparison with defects/damage type, and for subsequent consultation.

The classification enables to mark and order the structures in relation to the road artery and the relative mileage progression. The network has to be identified according to elements of the road register with updated traffic data together with the most stable geometric and material information.

The operative tool of this fundamental phase is the record card of the bridge, where the results of a visual inspection are transferred by a team which, after a first on-site reconnaissance (zero inspection), proceeds to identify the construction type and location, and intensity of the observed deteriorations. A dedicated section indicates any problems that could compromise the static nature of the structure such as: loss of verticality and undermining of piers and abutments, settlements, deficiencies related to the stability of the bearings and possible arch damages.

Experience has shown that most visual inspections do not require sophisticated tools although a preliminary phase of cleaning from spontaneous vegetation is essential to physically arrive at hidden parts of the bridge. A supplementary inspection may consequently require the use of ladders, platforms by bridge, boats, scaffolding or harnesses. The object of the minimum level inspection concerns the superstructure, the accessory devices, the bearings and the substructures. 


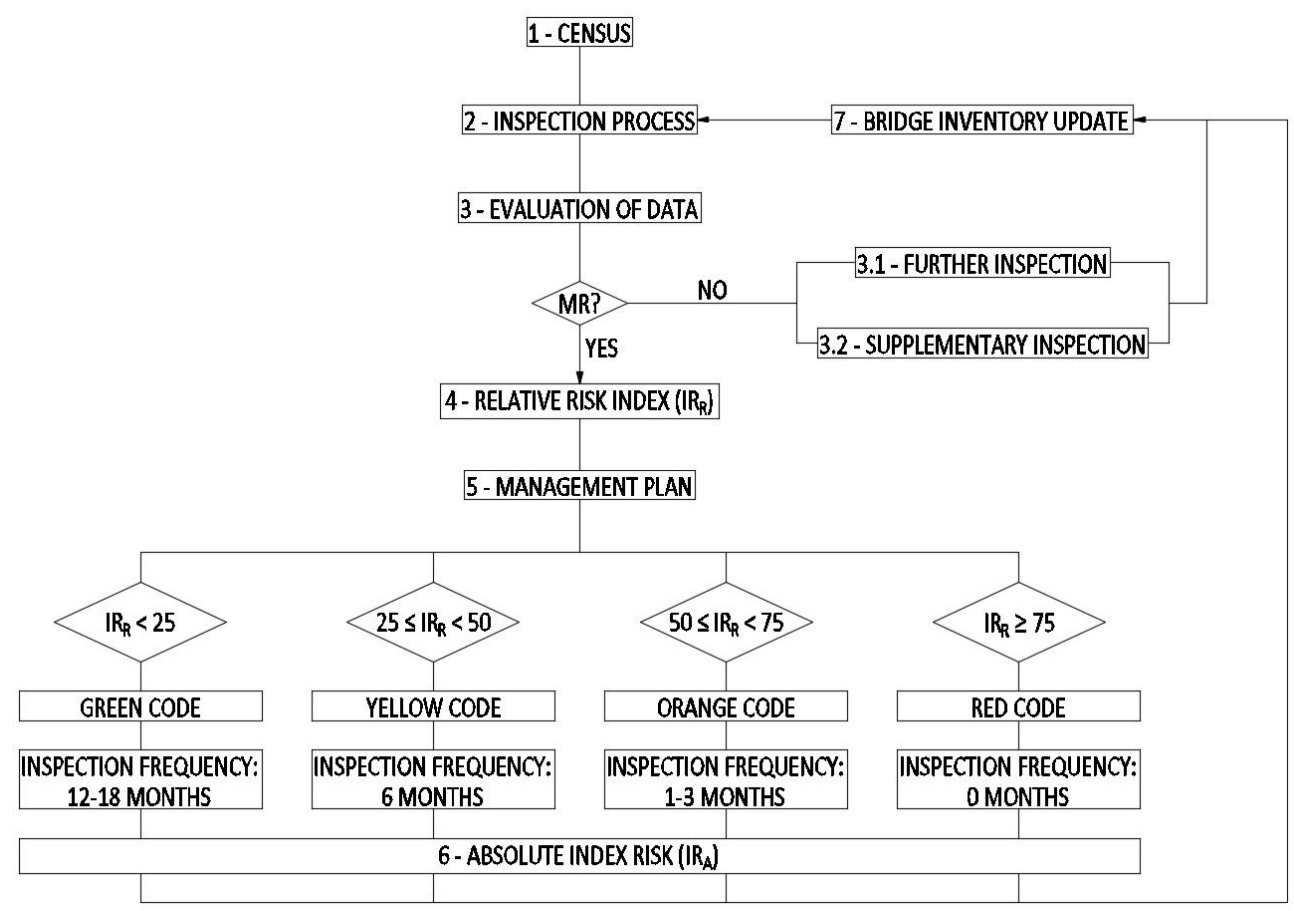

Figure 1 : Flow chart for the single bridge.

\subsection{Evaluation of the acquired data}

At the end of the visual inspections, an evaluation process of the data collected for the bridge under investigation is performed. This process determines if the inspection can be considered exhaustive and whether it is possible to calculate the risk indices. Although the possibility of not being able to make a judgement on the state of conservation of all the elements of a bridge is contemplated, there are some essential aspects to evaluate the success of an inspection. In particular, the results of a visual inspection are considered eligible when it has been possible to investigate at least $50 \%$ of the bridge elements and the crucial aspects strictly connected to the static of the structure such as: loss of verticality and undermining of piers and abutments, settlements, deficiencies related to the stability of the bearings and possible arch damages. At the end of each inspection a summary judgement is given (Table 1). Accordingly, it is possible to suspend the evaluation cycle and reschedule subsequent inspections to deepen the knowledge.

The evaluation of the acquired data permits to activate specific protocols associated to the management of a series of secondary elements of the structure which are fundamental for safety and, consequently, on management responsibilities, such as the type and status of the barriers, the state of the pavement, the joints, and the drainage system.

The considerations on the state of the restraint devices (barriers) deserve a dedicated protocol since the failure of a barrier is far more likely than the collapse of the structure. Three common scenarios were therefore considered in the method: the absence of restraint devices, their inadequacy, un-optimal behaviour due to damage. The state of conservation of the road pavement and joints, as well as the loss of project quotas, deserve appropriate investigation as they could be manifestations of structural damage or the creation of preferential paths for rainwater infiltration. 
Table 1: Rating of the inspection.

\begin{tabular}{cc}
\hline $\begin{array}{c}\text { Inspection } \\
\text { quality }\end{array}$ & Description \\
\hline Poor & $\begin{array}{l}\text { The information collected during the visual inspection does not permit to make a } \\
\text { judgment on the aspects that can potentially influence the static nature of the bridge } \\
\text { and the state of conservation of at least } 50 \% \text { of the elements of the bridge. A new } \\
\text { inspection is rescheduled. }\end{array}$ \\
\hline Fair & $\begin{array}{l}\text { The information collected during the visual inspection permits to express an } \\
\text { opinion on the static nature of the structure and to evaluate the state of conservation } \\
\text { of at least } 50 \% \text { of the elements of the bridge. It is possible to provide additional } \\
\text { inspections aimed at filling the gaps that emerged during the inspection. }\end{array}$ \\
\hline Good & $\begin{array}{l}\text { The information collected during the visual inspection permits to dissipate doubts } \\
\text { about the risks related to the static nature of the bridge and a judgment on the state } \\
\text { of conservation of at least } 75 \% \text { of the elements of the bridge is possible. }\end{array}$ \\
\hline
\end{tabular}

\section{Calculation of the relative risk index $I_{R}$}

The relative risk index is correlated to the overall degradation state of the bridge. The higher this number, the more serious is the general condition of the structure. The proposed indicator considers the recognized pathologies $I_{s c}$, the type of bridge $C_{t}$ and assumes the following expression:

$\mathrm{IR}_{\mathrm{R}}=\mathrm{I}_{\mathrm{sc}} \cdot \mathrm{C}_{\mathrm{t}}$

\subsection{Indicator of the state of conservation of the bridge}

$\mathrm{I}_{\mathrm{sc}}$ is the coefficient that quantifies the state of deterioration and is obtained as:

$\mathrm{I}_{\mathrm{sc}}=\sum_{\mathrm{i}=1}^{\mathrm{n}_{\text {deficiencies }}} \mathrm{W}_{\mathrm{i}} \cdot \mathrm{C}_{\text {int. }} \cdot \mathrm{E}_{\mathrm{i}}$

being $W_{i}$ the weight of the $i$-th deficiency, with a synthetic coefficient indicative of the intensity of the detected degrade $C_{i n t}$ and of an evolution coefficient $E_{i}$ which considers the change of the degradation of each deficiency between two consecutive inspections.

The main deficiencies can be divided into five classes, here listed in order of decreasing severity:

- Critical deficiencies: deficiencies potentially capable of compromising the static nature of the structure in the short term (pile or abutment heavily damaged);

- Severe deficiencies: deficiencies capable of rapidly evolving that need to be monitored (possible arch damages, cracks related to shear and bending);

- Significant deficiencies: deficiencies which, if not remedied, could lead to severe pathologies and/or a reduction in the load-bearing capacity of the structure in the long term (spalling, exposed bars, corrosion of reinforcement);

- Ordinary deficiencies: deficiencies that can lead to a suboptimal yield of the elements of the bridge, structural and accessories (honeycomb, plant growth);

- Common deficiencies: deficiencies which do not lead to significant short-term loss of functionality on the affected elements (abrasion, moisture spots).

The weights attributed to each deficiency are reported in Tables 2-9. 
Table 2 - Clear damage.

\begin{tabular}{llr}
\hline \multicolumn{1}{c}{ Deficiency } & Classification & $\mathrm{W}_{\mathrm{i}}$ \\
\hline Displaced pier & Critical & 100 \\
\hline Undermined pier & Critical & 100 \\
\hline Displaced abutment & Critical & 100 \\
\hline Damaged abutment & Critical & 100 \\
\hline Settlement (isostatic) & Critical & 100 \\
\hline Settlement (hyperstatic) & Critical & 140 \\
\hline Scour & Critical & 100 \\
\hline Damaged arch & Severe & 40 \\
\hline
\end{tabular}

Table 3 - Bearing deficiencies.

\begin{tabular}{llr}
\hline \multicolumn{1}{c}{ Deficiency } & Classification & $\mathrm{W}_{\mathrm{i}}$ \\
\hline Displacement / rotation & Critical & 100 \\
\hline Undermining & Critical & 100 \\
\hline
\end{tabular}

Table 4 - Deterioration of joints.

\begin{tabular}{llc}
\hline \multicolumn{1}{c}{ Deficiency } & Classification & $\mathrm{W}_{\mathrm{i}}$ \\
\hline Vertical settlement in the carriageway pavement & Common & 1 \\
\hline Transition strip damaged & Ordinary & 2 \\
\hline Bridging plate deteriorated & Ordinary & 2 \\
\hline Absent gutter & Significant & 10 \\
\hline Leaking gutter & Significant & 10 \\
\hline Asphalt cracks & Common & 1 \\
\hline
\end{tabular}

Table 5 - Concrete structure deficiencies.

\begin{tabular}{llc}
\hline \multicolumn{1}{c}{ Deficiency } & Classification & $\mathrm{W}_{\mathrm{i}}$ \\
\hline Transverse cracks & Severe & 20 \\
\hline Diagonal cracks & Severe & 20 \\
\hline Horizontal cracks & Ordinary & 2 \\
\hline Vertical cracks & Ordinary & 2 \\
\hline Longitudinal cracks & Ordinary & 2 \\
\hline Spalling & Significant & 10 \\
\hline Collision damage & Significant & 10 \\
\hline Honeycomb & Ordinary & 2 \\
\hline Moisture spots & Common & 1 \\
\hline Corrosion of reinforcement & Significant & 10 \\
\hline Exposed bar / stirrups & Significant & 10 \\
\hline
\end{tabular}

Table 6 - Prestressed concrete deficiencies.

\begin{tabular}{llc}
\hline \multicolumn{1}{c}{ Deficiency } & Classification & $\mathrm{W}_{\mathrm{i}}$ \\
\hline Crack near anchorage & Common & 1 \\
\hline Unsealed anchorage & Ordinary & 2 \\
\hline Spalling near anchorage & Common & 1 \\
\hline Crack along web & Ordinary & 2 \\
\hline Crack at the bottom surface & Ordinary & 2 \\
\hline Exposed sheath & Ordinary & 2 \\
\hline Corrosion of the prestressed tendon & Critical & 100 \\
\hline
\end{tabular}


Table 7 - Masonry deficiencies.

\begin{tabular}{llc}
\hline \multicolumn{1}{c}{ Deficiency } & Classification & $\mathrm{W}_{\mathrm{i}}$ \\
\hline Transverse cracks & Severe & 20 \\
\hline Diagonal cracks & Severe & 20 \\
\hline Horizontal cracks & Ordinary & 2 \\
\hline Vertical cracks & Significant & 10 \\
\hline Longitudinal cracks & Significant & 10 \\
\hline Poor interlocking & Significant & 10 \\
\hline Losses of material & Significant & 10 \\
\hline Plant growth & Ordinary & 2 \\
\hline Pulverization & Significant & 10 \\
\hline Exfoliation & Common & 1 \\
\hline Moisture spots / Efflorescence & Common & 1 \\
\hline
\end{tabular}

Table 8 - Steel structural elements deficiencies.

\begin{tabular}{llc}
\hline \multicolumn{1}{c}{ Deficiency } & Classification & $\mathrm{W}_{\mathrm{i}}$ \\
\hline Welding defects & Significant & 10 \\
\hline Crack in weld & Severe & 20 \\
\hline Peeling paint & Common & 1 \\
\hline Failed rivets & Severe & 20 \\
\hline Loose bolts & Significant & 10 \\
\hline Failed bolts & Severe & 20 \\
\hline Permanent deformation (steel members) & Significant & 10 \\
\hline Water stagnation & Common & 1 \\
\hline Damaged connection & Severe & 20 \\
\hline Corrosion & Severe & 20 \\
\hline Surface rust & Common & 1 \\
\hline
\end{tabular}

Table 9 - Accessories deficiencies.

\begin{tabular}{llc}
\hline \multicolumn{1}{c}{ Deficiency } & Classification & $\mathrm{W}_{\mathrm{i}}$ \\
\hline Wearing surface: potholes/ruts/damage & Common & 1 \\
\hline Vertical settlement in the approach slab behind the abutment(s) & Common & 1 \\
\hline Railing: damaged/poorly anchored & Significant & 10 \\
\hline Guardrail: damaged/poorly anchored & Significant & 10 \\
\hline Deteriorated kerb & Ordinary & 2 \\
\hline Sidewalk: pavement in poor condition & Common & 1 \\
\hline Drainage system: blocked scupper(s) & Significant & 10 \\
\hline Drainage system: short pipes & Significant & 10 \\
\hline Drainage system: clogged pipes & Significant & 10 \\
\hline Drainage system: damaged pipes & Significant & 10 \\
\hline Light pole: poorly anchored & Common & 1 \\
\hline Light pole: damaged & Common & 1 \\
\hline Light pole: rusted & Common & 1 \\
\hline External attachment & Common & 1 \\
\hline
\end{tabular}

The intensity of degradation coefficient listed in Table 10 is proportional to the determined level. The lack of knowledge is penalized with the highest value.

The coefficient $E_{i}$ takes into account the evolution of the $\mathrm{i}$-th pathology. Three scenarios are possible: improvement, worsening or stable state (see Table 11). Its numerical value 
is based on the increment $\Delta_{\mathrm{i}}$ between the intensity coefficient $\mathrm{C}_{\mathrm{int}}$ assigned during the most recent inspection " $\mathrm{x}$ " and the previous one "x-1".

$\Delta_{\mathrm{i}}=\mathrm{C}_{\text {int. x }}-\mathrm{C}_{\text {int. x }-1}$

The implementation of improvement maintenance interventions between one inspection and the next determines a value of $\Delta_{i}$ less than zero, for which the evolutionary coefficient becomes unitary as for stable situations $\left(\Delta_{i}=0\right)$.

The evolutionary coefficient takes respectively the value 1.5 or 2 if the deficiency, between an inspection and the following, with a constant temporal frequency, it worsens more or less suddenly.

Table 10 : Intensity coefficient $\mathrm{C}_{\text {int. }}$

\begin{tabular}{cccc}
\hline & \multicolumn{3}{c}{$\mathrm{C}_{\text {int }}$} \\
\hline No damage & Mild & Severe & Undetectable \\
0 & 0.25 & 0.75 & 1 \\
\hline
\end{tabular}

Table 11 : Evolution coefficient $\mathrm{E}_{\mathrm{i}}$

\begin{tabular}{clc}
\hline$\Delta_{\mathrm{i}}$ & Situation & $\mathrm{E}_{\mathrm{i}}$ \\
\hline$<0$ & Effective maintenance & 1 \\
\hline$=0$ & Stable situation & 1 \\
\hline$>0$ & Degradation increases & 1.5 or 2 \\
\hline
\end{tabular}

\subsection{Indicator coefficient of the bridge type}

The historical evolution of knowledge has created a sensitivity and a technical awareness that defines when a structure can be more or less exposed to the effects of material degradation or movements induced by slow active processes during long periods of exercise. This is the case of arch bridges, where possible trigger of localized breakage phenomena are announced by the formation of hinges that make the structure more and more labile (CNR-DT213, 2015). In the case of girder bridges, with the same span and loads, the isostatic scheme is subjected to greater and less distributed stressing actions compared to the continuous girder scheme (Leonhardt, 1979). It follows that the materials of the former are more exploited. On the other hand, bridges with continuous girder are more affected by possible subsidence in foundations than bridges with isostatic girder (Petrangeli, 1996).

Culvert structures are less critical, usually used to overcome limited spans of small subways, small waterways and artificial canals and it is not uncommon to identify crossing works with mixed structural typologies.

From the maintenance point of view, some constructions are more problematic than others. An emblematic example are the "Gerber" type beam bridges, now in disuse. Experience has shown that, without careful maintenance, the Gerber hinges are subject to severe degradation and that this is the cause of potential fragile failure of the deck (Kun et al., 2015).

Morevoer, the presence of water infiltrations determines an exponential evolution of degradation over time. Cracks or discontinuities in the road pavement or defects in the structural joints between the different spans can represent a preferential way for the 
penetration of water into the substructures. Not infrequent are the absence or inefficiency of the collection and disposal systems of the platform water.

Isostatic girder bridges require roadway joints at each end and will therefore potentially be more exposed to degradation. On the other hand, the great advantage of continuous beams is the absence of joints on great bridge lengths (Leonhardt, 1979).

Steel bridges can present problems at the level of the nodes where brittle rupture may occur due to corrosive phenomena induced by water stagnation and / or the action of salt used for winter road maintenance (Shi et al., 2010, Autelitano et al, 2019).

Therefore, specific bridge type has intrinsic characteristics which are potential sources of deterioration and which can lead to more or less serious consequences for the safety of the structure.

Table 12: Typological coefficient $\mathrm{C}_{\mathrm{t}}$

\begin{tabular}{lccc}
\hline & $\mathrm{C}_{\mathrm{t}}=\alpha \cdot \beta$ & & \\
\hline Static scheme & $\alpha$ & Type & $\beta$ \\
\hline \multirow{2}{*}{ Isostatic beam } & & Gerber hinges & 2.0 \\
\cline { 3 - 4 } & 1.0 & Truss girders & 1.5 \\
\cline { 3 - 4 } & & Simply supported & 1.2 \\
\hline Continuous beam & 1.0 & - & 1.0 \\
\hline Arch & 1.0 & Masonry & 1.0 \\
\hline Arch & 1.0 & Concrete & 1.0 \\
\hline Arch with two hinges & 1.25 & Concrete & 1.2 \\
\hline Arch with three hinges & 1.5 & Concrete & 1.2 \\
\hline Mixed & 1.0 & - & 1.2 \\
\hline Culvert & 0.8 & - & 1.0 \\
\hline
\end{tabular}

To take these aspects into account, a typological coefficient $C_{t}$ has been introduced, obtained as the product of two indicators referable to the type of the static scheme of the bridge $(\alpha)$ and the predisposition of the structure to fragile failures $(\beta)$. The suggested values (Table 12) underlie the increase or decrease in the $C_{t}$ coefficient in relation to the hazard typical of each static scheme and the predisposition to fragile breakage phenomena.

\section{Definition of management plans}

The relative risk index $I R_{R}$ calculated for each bridge allows to define, by analogy with the codes of the management of the road infrastructure maintenance systems (http://www.autostrade.it/it/la-nostra-rete/operazioni-invernali), numerical intervals that can be communicated or quickly described with a color code that underlies the frequency and modalities of the activities.

The proposed values of Table 13 have been calibrated in such a way that, if a serious pathology is detected during the inspection, which is associated with a severe intensity, the bridge is directly assigned a red code. Similarly, the presence of one or two serious pathologies of mild intensity determine the application of the yellow and orange codes respectively. The numerical ranges have given a positive response; however, these can be remodelled and calibrated according to specific needs by the managing authority. 
Table 13: Management plans

\begin{tabular}{|c|c|c|c|}
\hline Code & $\mathrm{IR}_{\mathrm{R}}$ & Description & $\begin{array}{l}\text { Inspection } \\
\text { frequency }\end{array}$ \\
\hline Green & $\mathrm{IR}_{\mathrm{R}}<25$ & $\begin{array}{l}\text { The state of the bridge is fully defined. } \\
\text { Supplementary inspections are not necessary. }\end{array}$ & $12 \div 18$ months \\
\hline Yellow & $25 \leq \mathrm{IR}_{\mathrm{R}}<50$ & $\begin{array}{l}\text { The state of the bridge is defined with observation } \\
\text { of irrelevant critical issues. Schedule control } \\
\text { inspection or supplementary inspections if there is a } \\
\text { cognitive deficit. }\end{array}$ & 6 months \\
\hline Orange & $50 \leq \mathrm{IR}_{\mathrm{R}}<75$ & $\begin{array}{l}\text { The state of the bridge is defined with evidence of } \\
\text { significant critical issues. }\end{array}$ & $1 \div 3$ months \\
\hline Red & $\mathrm{IR}_{\mathrm{R}} \geq 75$ & $\begin{array}{l}\text { The state of the bridge is critical or the knowledge } \\
\text { framework is incomplete regarding potential safety- } \\
\text { relevant hazards. The intervention is urgent. The } \\
\text { inspection process resumes only after the } \\
\text { implementation of the intervention. } \\
\text { The vehicle traffic regulation / suspension process } \\
\text { is implemented immediately. }\end{array}$ & 0 months \\
\hline
\end{tabular}

\section{Prioritization of interventions}

The assignment of a specific management plan to the individual bridge is the result of a mere assessment of its state of conservation. Within each management plan, the need to plan an order of priority of intervention arises and a targeted use of economic resources.

The introduction of an Absolute Risk Index $I_{A}$ is needed, which is able to relate the infrastructure to the context in which it is inserted and to the importance it has within the managed road network. This index is defined as:

$\mathrm{IR}_{\mathrm{A}}=\mathrm{I}_{\mathrm{imp}} \cdot \mathrm{I}_{\mathrm{c}} \cdot \mathrm{IR}_{\mathrm{R}}$

where $I_{i m p}$ is an indicator of the importance of the bridge, $I_{c}$ is an indicator of the complexity of the bridge and $\mathrm{IR}_{\mathrm{R}}$ is the Relative Risk Index.

\subsection{Indicator of Importance $\mathrm{I}_{\mathrm{imp}}$}

$\mathrm{I}_{\mathrm{imp}}$ is indicative of the strategic importance of the bridge, in consideration of the impacts that its inefficiency or its partial or total interdiction to vehicular transit can cause. It is analytically expressed by a linear combination of four coefficients, defined on the basis of the cataloguing data acquired in the census phase:

$\mathrm{I}_{\text {imp. }}=\left(\frac{\mathrm{k}_{\mathrm{c}}+\mathrm{k}_{\mathrm{t}}+\mathrm{k}_{\mathrm{s}}}{100}+1\right)+\mathrm{k}_{\mathrm{i}}$

The $\mathrm{k}_{\mathrm{c}}$ coefficient takes into account the geometric and functional classification of the road where the bridge accomplishes its service, according to the Italian national legislation (Table 14 - Giuliani et al., 2008).

The coefficient $\mathrm{k}_{\mathrm{t}}$ is an indicator of the traffic volumes characterizing the road where the bridge is located, according to a classification based on the Annual Average Daily Traffic (AADT) and on the relative percentage of traffic for industrial vehicles or buses (Table 15). 
Table 14: Coefficient $\mathrm{k}_{\mathrm{c}}$

\begin{tabular}{clc}
\hline Network hierarchy & Type of service & $k_{c}$ \\
\hline Primary & Transit and flow & 30 \\
\hline Main & Distribution & 20 \\
\hline Secondary & Penetration & 10 \\
\hline Local & Access & 0 \\
\hline
\end{tabular}

Table 15: Coefficient $\mathrm{k}_{\mathrm{t}}$

\begin{tabular}{ccc}
\hline Traffic level & Description & $k_{t}$ \\
\hline 1 & AADT $<1000$ and Truck $/$ Bus $<5 \%$ & 0 \\
\hline 2 & $1000<$ AADT and Truck $/$ Bus $<10 \%$ & 15 \\
\hline 3 & $1000<$ AADT and Truck / Bus $>10 \%$ & 30 \\
\hline
\end{tabular}

The coefficient $\mathrm{k}_{\mathrm{s}}$ is an indicator of the strategic importance of the structure. The proposed numerical values of this indicator derive from a logical process of assessment of the actual importance of the full safety functionality of the bridge, in comparison with the existence of any alternative routes and their extension (Figure 2).

The $\mathrm{k}_{\mathrm{i}}$ coefficient is an indicator of higher strategic importance of the structure and intervenes in those situations where a deficit in the structural integrity of the bridge and all its accessory parts determines a prejudice on the safety of the specialized routes for exceptional loads, national military and civil emergency. For example, those bridges which, although belonging to non-hierarchically important routes, still exceed the primary road networks. $\mathrm{k}_{\mathrm{i}}$ coefficient assumes value 0 if the bridge does not interfere with higher order roads or is not of strategic importance and a value of 0.4 otherwise.

In conclusion, $\mathrm{I}_{\mathrm{imp}}$ assumes values potentially included between 1 (minor importance) and 2.4 (major importance).

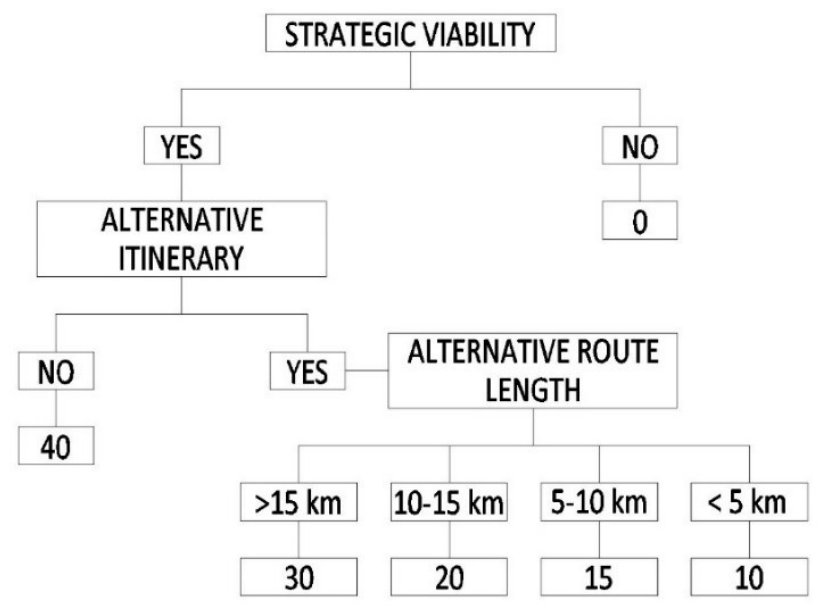

Figure 2: Criterion for the quantification of the coefficient $\mathrm{k}_{\mathrm{s}}$

\subsection{Complexity Indicator $\mathrm{I}_{\mathrm{c}}$}

The failure of a complex structure, conceived probably to cover medium-large lengths, involves restoration costs higher than those necessary for small bridges. Optimization of the economic burdens needed for the maintenance of bridges is improved if an indicator 
representative of the structural complexity $I_{c}$ is introduced. $I_{c}$ depends on the number of spans or the piers $\left(\mathrm{k}_{\mathrm{p}}\right)$, on the span with greater length $\left(\mathrm{k}_{\mathrm{Lmax}}\right)$ and on the presence of piers in the riverbed $\left(\mathrm{k}_{\mathrm{pa}}\right)$ :

$\mathrm{I}_{\mathrm{c}}=\mathrm{k}_{\mathrm{p}}+\mathrm{k}_{\mathrm{Lmax}}+\mathrm{k}_{\mathrm{pa}}$

where $k_{p}=1,1+\log _{10}\left(\sqrt{n_{p}}\right)$ and $n_{p}=$ number of bridge piers.

The values of the $\mathrm{k}_{\mathrm{Lmax}}$ coefficient are indicated in Table 16 while $\mathrm{k}_{\mathrm{pa}}$ is a coefficient that assumes a zero value or equal to 0.2 if there are piers in the riverbed, due to the greater susceptibility to erosion and potentially undermining phenomena.

Table 16: Coefficient $\mathrm{k}_{\mathrm{Lmax}}$

\begin{tabular}{cc}
\hline Maximum lenght & $\mathrm{k}_{\mathrm{Lmax}}$ \\
\hline $0<\mathrm{L}_{\max }<5 \mathrm{~m}$ & 0 \\
\hline $5 \mathrm{~m} \leq \mathrm{L}_{\max }<15 \mathrm{~m}$ & 0.05 \\
\hline $\mathrm{L}_{\max } \geq 15 \mathrm{~m}$ & 0.10 \\
\hline
\end{tabular}

\section{Examples of application of the method}

The proposed methodology has been applied to four concrete girder bridges.

Case study A - The structure is a five-spans "Gerber" type beam bridge located in a strategic road (Fig. 3). The three main spans are $27 \mathrm{~m}$ long whereas the side spans are $21.6 \mathrm{~m}$ long. The external girders and the cross beams are affected by severe spalling and corrosion of reinforcement, abrasion, moisture spots due to water leakage (Figs. 4a-c). The deck results in critical condition. The main degradation is localised in the "Gerber" hinges, where important detachments of concrete from the beams are observed. Furthermore, the metal bearings are strongly oxidized (Fig. 4d). Abutments and piers are in in good condition. The pavement presents superficial cracks, especially near the joints and bridge extremities. The indicator $\mathrm{I}_{\mathrm{sc}}$ is equal to 96.75 and the typological coefficient is equal to 2. By applying equation (1) the relative risk index $I_{R}$ becomes 193.5.

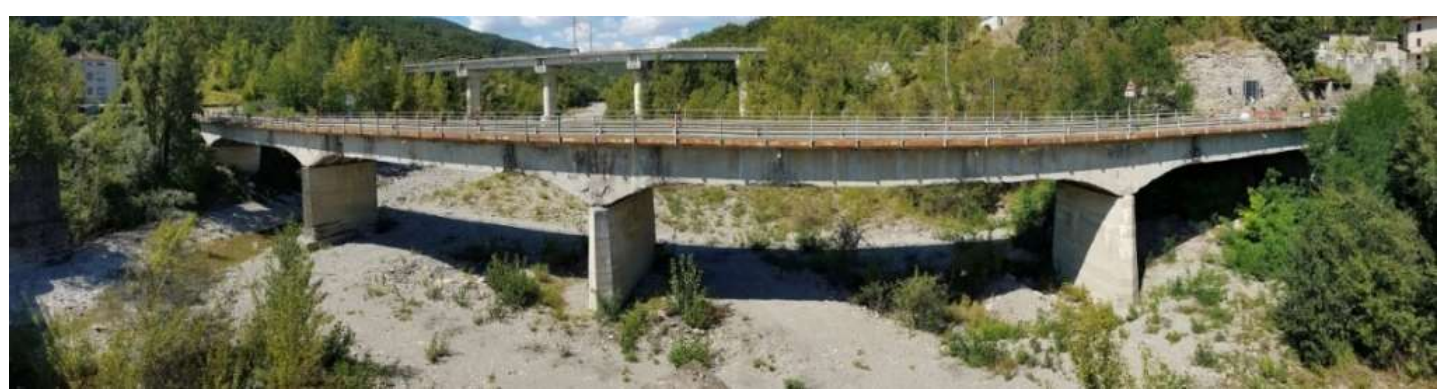

Figure 3: Side view. 


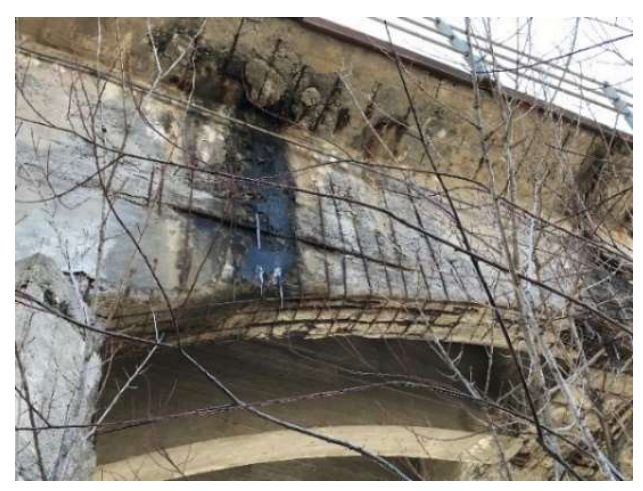

(A)

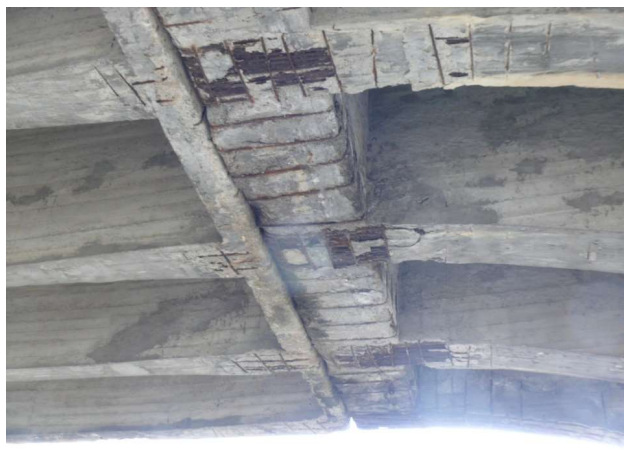

(C)

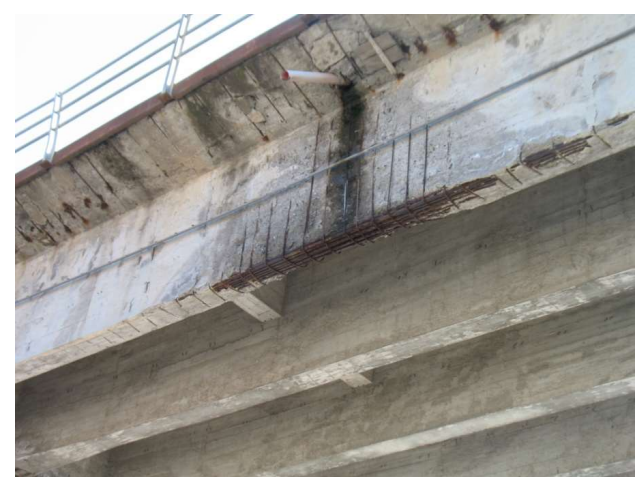

(B)

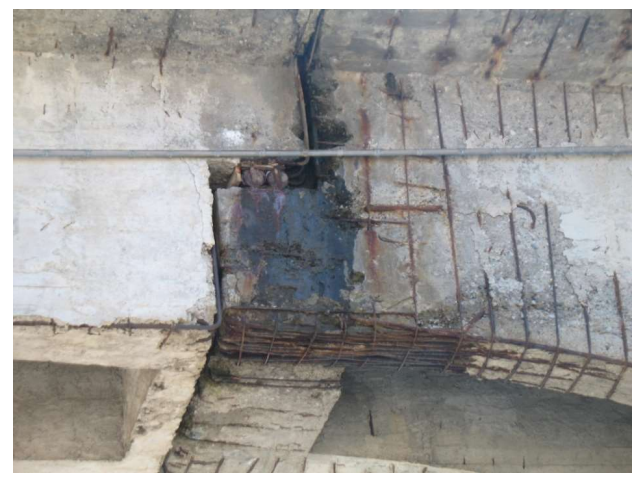

(D)

Figure 4: (A) Moisture spots. (B) Corrosion of reinforcement. (C) Exposed bars. (D) Degradation of joint and metal bearing.

Case study B - The bridge is a three-spans continuos bridge located in a strategic road (Figure 5). The main span is about $27.10 \mathrm{~m}$ long, and the side spans are $9.20 \mathrm{~m}$ long. The external girders of the bridge are affected by: abrasion, moisture spots and minor honeycomb. Along the deck, it is possible to find areas with concrete spalling and exposed reinforcements (Figure 6a). The inspection of the substructure highlights the crumbling of one abutment (Figure 6b). The absence of end joints causes a strong cracking of the pavement. The indicator $I_{s c}$ is equal to 127.75 . Being a continuos bridge, the typological coefficient is equal to 1 so the relative risk index $I R_{R}$ associated results equal to 127.75.

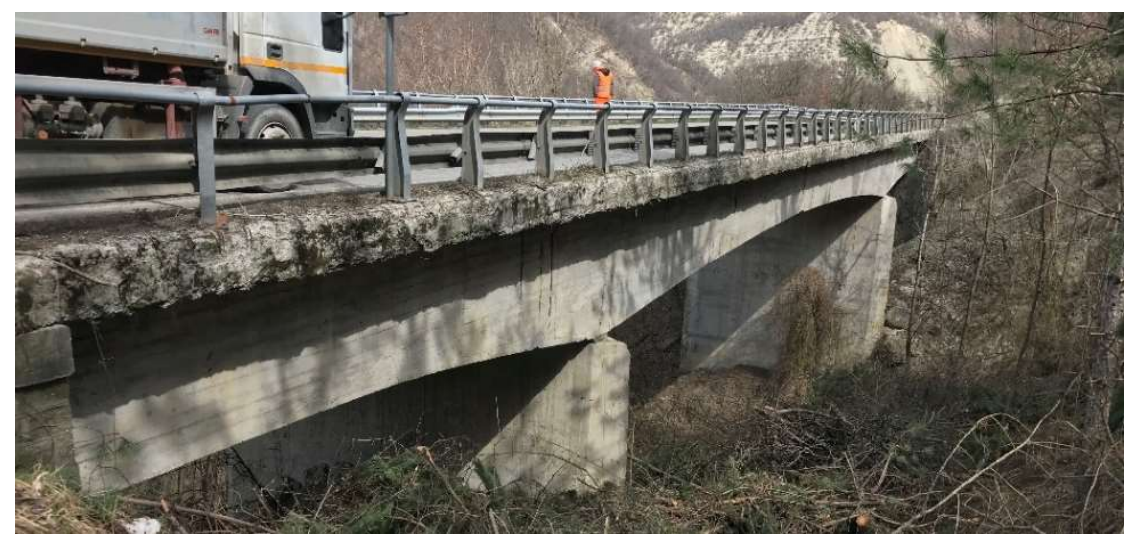

Figure 5: Side view. 


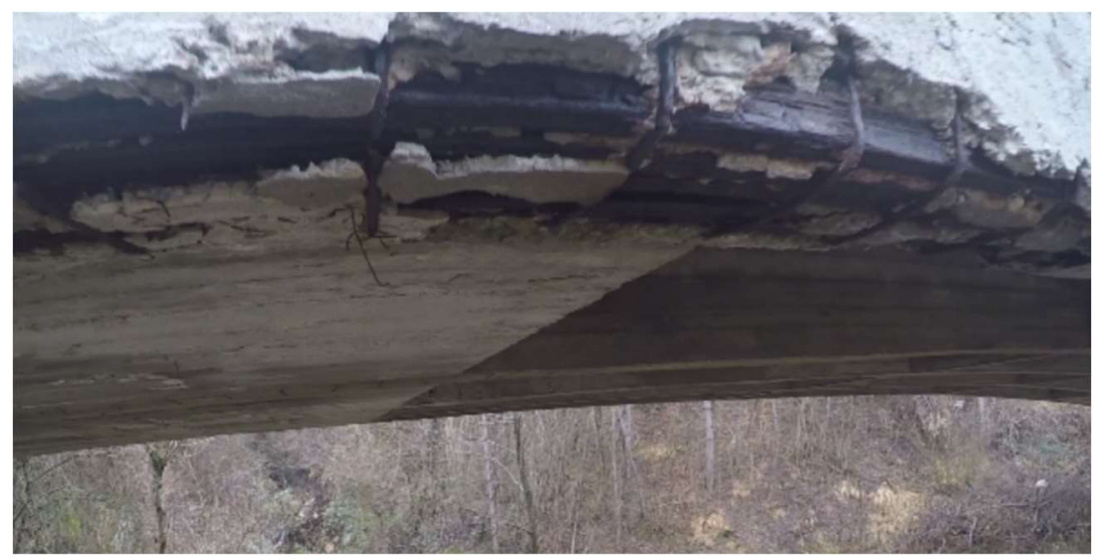

(A)

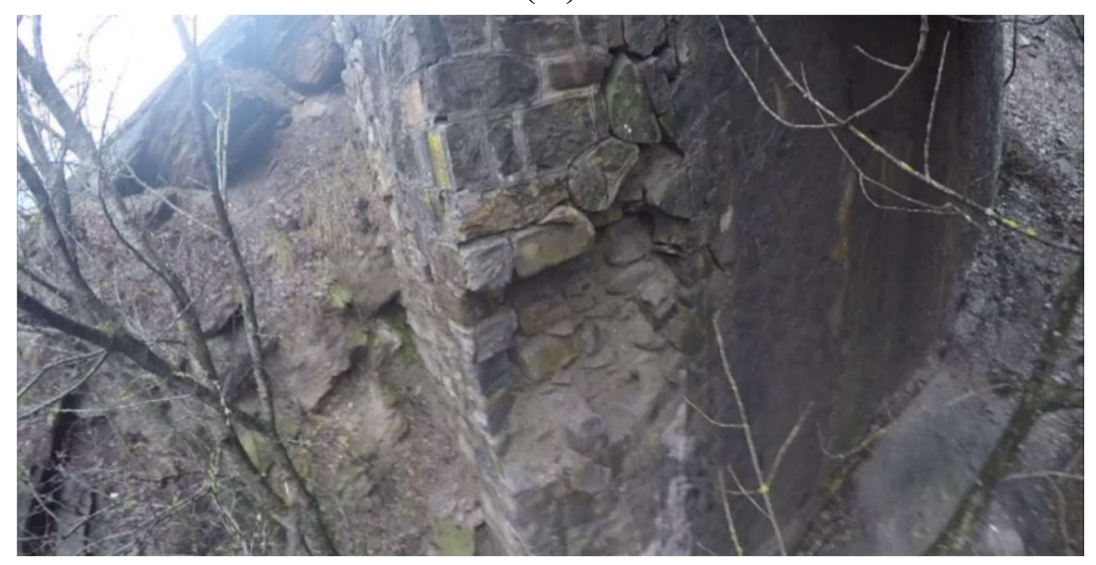

(B)

Figure 6: A) Exposed reinforcement. B) Crumbled abutment.

Case study $\mathbf{C}$ - The bridge is a three-spans isostatic bridge located in a strategic road (Figure 7). The main span is about $11.30 \mathrm{~m}$ long, and the side spans are $10.60 \mathrm{~m}$ long. The state of the deck is quite severe. Girders are affected by spalling and corrosion of reinforcement near the bearings, on top of the piers and abutments (Figure 8a, 8b). The indicator $I_{\mathrm{sc}}$ is equal to 53.25 . Being an isostatic bridge, the typological coefficient is equal to 1.2 and the relative risk index $I_{R}$ associated is equal to 63.9.

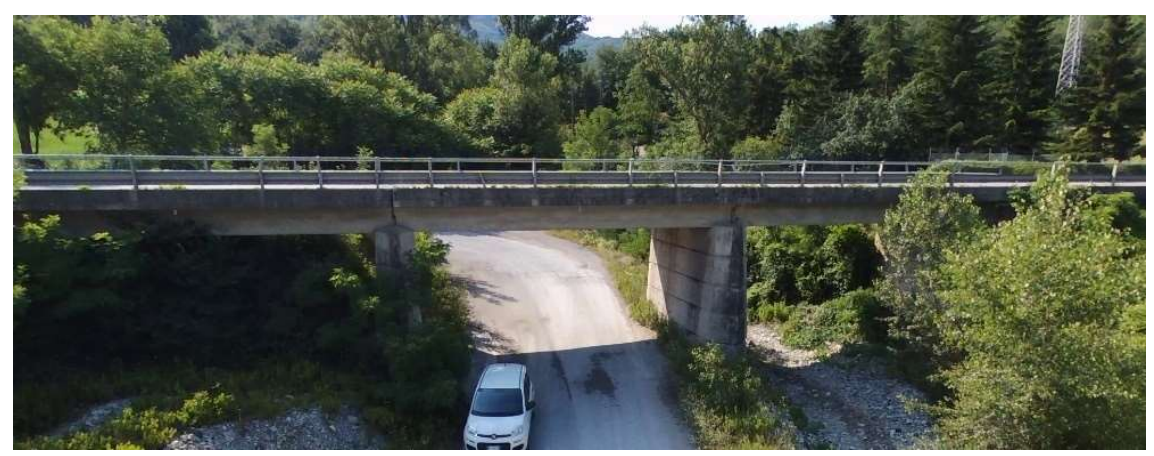

Figure 7: Side view. 


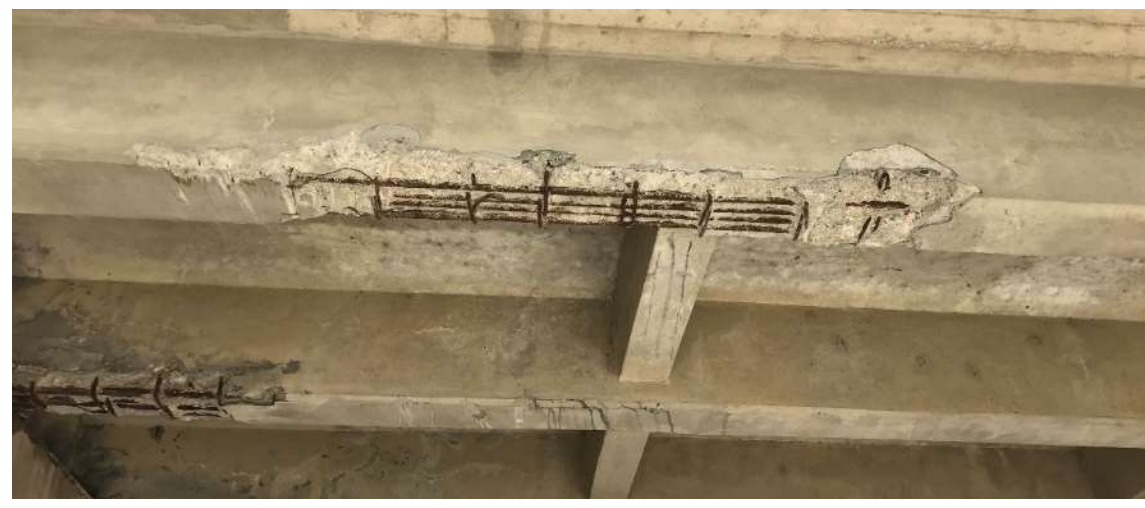

(A)

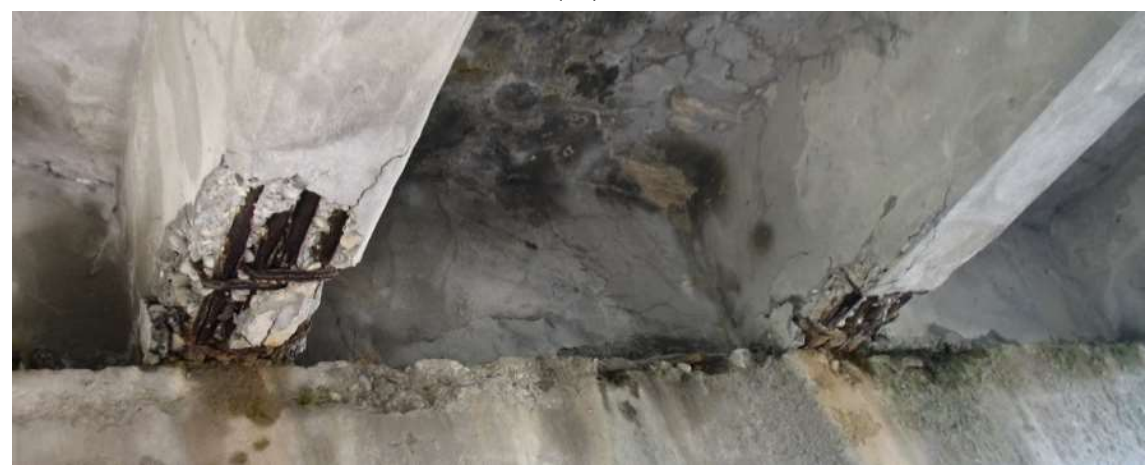

(B)

Figure 8: (A) Exposed reinforcement. (B) Spalling near bearings.

Case study D - The bridge is a single span isostatic bridge (Figure 9). The span is about $14.40 \mathrm{~m}$ long. The deck, with reinforced concrete beams and collaborating slab, is simply supported. In the span there are four cross beams: two at the head and two intermediate. Both of the two girders suffer of spalling and corriosion of reinforcement near the bearings (Figure 10a, 10b). The indicator $\mathrm{I}_{\mathrm{sc}}$ is equal to 51.50 . Being an isostatic bridge, the typological coefficient is equal to 1.2 and the relative risk index $I_{R}$ associated is equal to 61.80 .

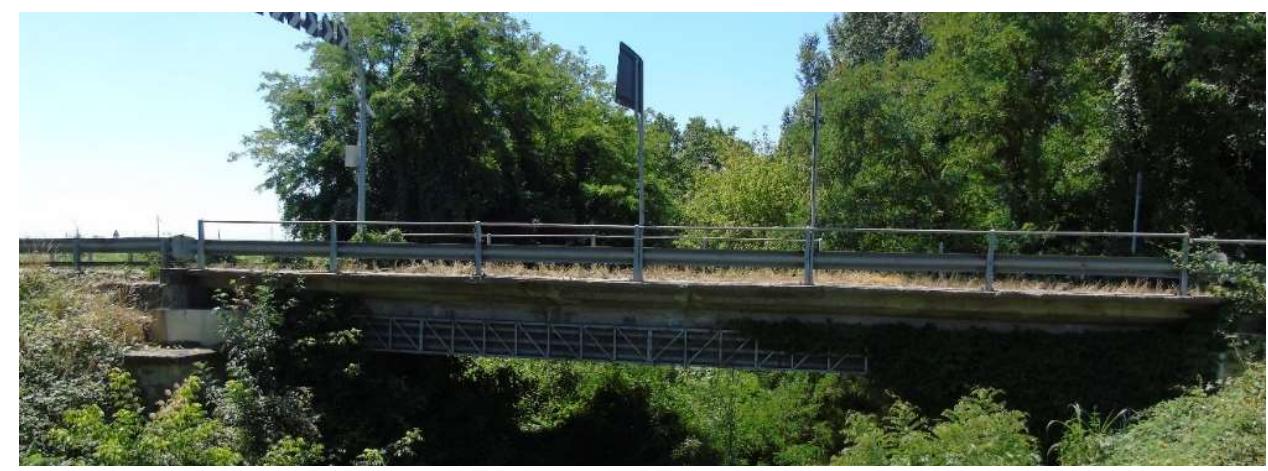

Figure 9: Side view. 


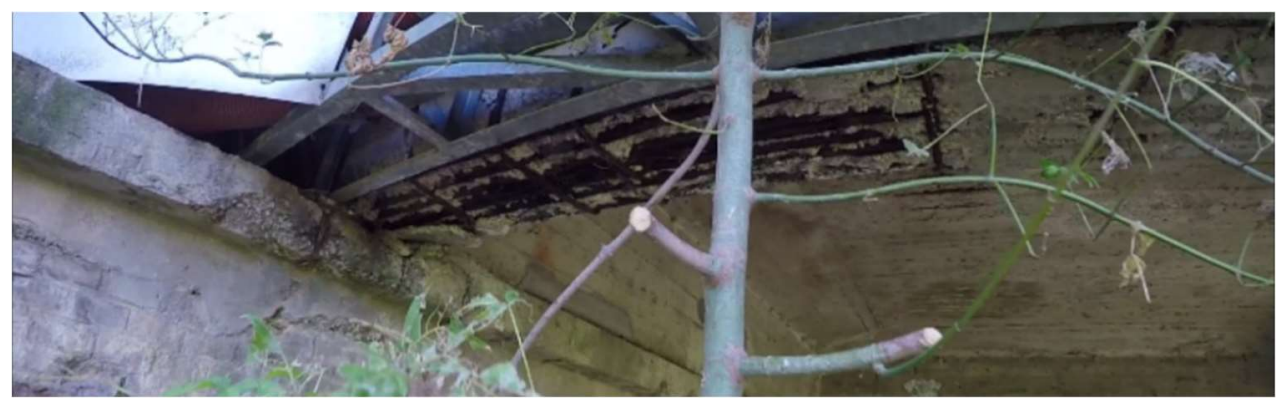

(A)

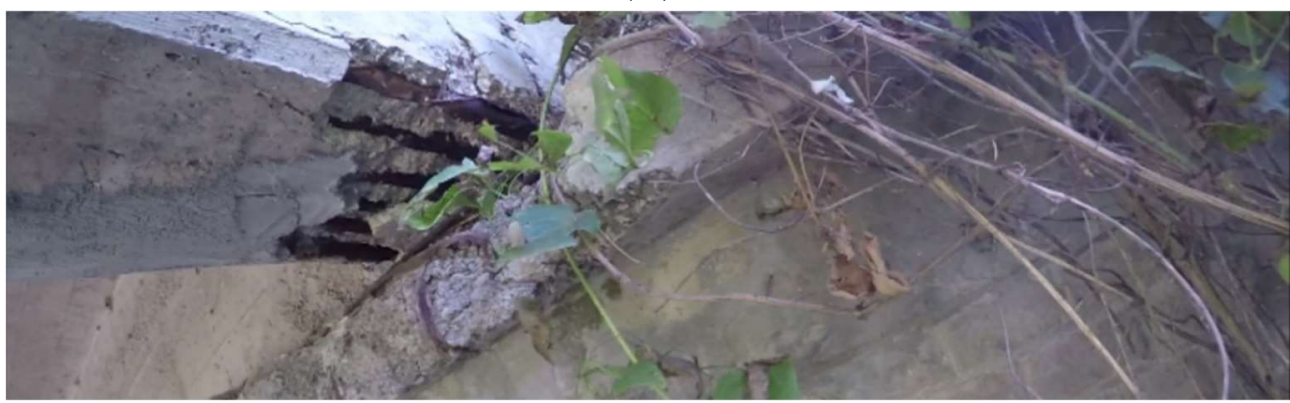

(B)

Figure 10: (A) Exposed reinforcement. (B) Spalling near bearings.

Based on the calculated $I_{R}$ indices, it is possible to associate a suitable management plan to each bridge presented. Case studies $\mathrm{A}$ and $\mathrm{B}$ have a relative risk index higher than 75; therefore they are given a management plan identified by red code. Case studies $\mathrm{C}$ and $\mathrm{D}$, whose relative index is between 50 and 75 , are assigned a management plan identified by orange code.

The intervention priority is assigned calculating the absolute risk indices $\left(\operatorname{IR}_{\mathrm{A}}\right)$. All the parameters involved in the definition of the absolute risk index are reported in Table 17 for each case study. At the end of the evaluation process, it is clear that cases $\mathrm{A}$ and $\mathrm{C}$ have priority over cases B and D within their management plans.

Table 17 : Calculation of the absolute risk index

\begin{tabular}{ccccc}
\hline Parameter & Case $A$ & Case $B$ & Case C & Case D \\
\hline $\mathrm{I}_{\mathrm{sc}}$ & 96.75 & 127.75 & 53.25 & 51.5 \\
\hline $\mathrm{C}_{\mathrm{t}}$ & 2 & 1 & 1.2 & 1.2 \\
\hline $\mathrm{IR}_{\mathrm{R}}$ & 193.5 & 127.75 & 63.9 & 61.8 \\
\hline CODE & Red & Red & Orange & Orange \\
\hline $\mathrm{k}_{\mathrm{c}}$ & 20 & 20 & 20 & 20 \\
\hline $\mathrm{k}_{\mathrm{t}}$ & 15 & 15 & 15 & 15 \\
\hline $\mathrm{k}_{\mathrm{s}}$ & 20 & 20 & 20 & 10 \\
\hline $\mathrm{k}_{\mathrm{i}}$ & 0 & 0 & 0 & 0 \\
\hline $\mathrm{I}_{\mathrm{imp}}$ & 1.55 & 1.55 & 1.55 & 1.45 \\
\hline $\mathrm{k}_{\mathrm{Lmax}}$ & 0.1 & 0.1 & 0.05 & 0.05 \\
\hline $\mathrm{k}_{\mathrm{p}}$ & 1.4 & 1.25 & 1.25 & 1 \\
\hline $\mathrm{k}_{\mathrm{p} \text {.a. }}$ & 0.2 & 0.2 & 0.2 & 0 \\
\hline $\mathrm{I}_{\mathrm{c}}$ & 1.7 & 1.55 & 1.3 & 1.05 \\
\hline $\mathrm{IR}_{\mathrm{A}}$ & 510.2 & 307 & 128.8 & 94 \\
\hline
\end{tabular}




\section{Conclusions}

A practical tool to define the hierarchy of the mantainence plain of the infrastructural heritage is proposed. The application of the proposed approach demonstrates that the complexity of the building plays a fundamental role in planning the interventions. Morevoer, the results are influenced by the role played at a strategic level by the road artery where the bridge is located.

The proposed procedure is not intended to be a substitute or an improvement compared to what is reported in the "Linee guida per la classificazione e gestione del rischio, la valutazione della sicurezza ed il monitoraggio dei ponti esistenti" during the experimentation phase. Rather, it is configured as a quick and lean tool that allows to obtain a hierarchization of the structures in charge of the local Entities.

In the future, the proposed strategy will be refined by testing the current model on a larger sample of bridges and its possible interaction with the results obtainable from the application of the Guidelines is being studied.

\section{References}

Ryall, M.J. (2010) "Bridge Management”, 2 Ed., Butterworth - Heinemann, Oxford.

Petrangeli, M.P. (1993) "Progettazione e costruzione di ponti con cenni di patologia e diagnostic delle opere esistenti”, Casa Editrice Ambrosiana, Milano.

Leonhardt, F. (1979) "Vol.VI: I ponti: Dimensionamento - Tipologia - Costruzione”, Edizioni di Scienza e Tecnica, Milano.

Scutaru, M.C., Comisu, C. C., Boaca, G., Taranu, N. (2018) “A brief comparison among different countries around the world", Proceedings from the 9th International Conference on Bridge Maintenance, Safety and Management, (N.Powers, D. M. Frangopol, R. Al-Mahaidi, C. Caprani eds.), Taylor \& Francis Group, Melbourne.

Fujino, Y. (2018) "Bridge maintenance, renovation and management - Research and Development of governmental program in Japan", Proceedings from the 9th International Conference on Bridge Maintenance, Safety and Management, (N.Powers, D. M. Frangopol, R. Al-Mahaidi, C. Caprani eds.), Taylor \& Francis Group, Melbourne.

Joshi, S., Naga, N., Rajesh, U. (2018) "Experience of Management of Bridges Prior to and Post Evaluation of BMS on NH network of India", Proceedings from the 9th International Conference on Bridge Maintenance, Safety and Management, (N.Powers, D. M. Frangopol, R. Al-Mahaidi, C. Caprani eds.), Taylor \& Francis Group, Melbourne.

Hallerman, N., Taraben, J., Morghenthal, G. (2018) "BIM related workflow for an imagebased deformation monitoring of Bridges, Proceedings from the 9th International Conference on Bridge Maintenance, Safety and Management, (N.Powers, D. M. Frangopol, R. Al-Mahaidi, C. Caprani eds.), Taylor \& Francis Group, Melbourne.

Di Prisco, M., Colombo, M., Martinelli, P., Coronelli, D. (2018) "The technical causes of the collapse of Annone overpass on SS.36", Italian Concrete Days 2018, Lecco, Italy, pp. 1-16.

Miyamoto, A., Motoshita, M. (2015) "Development and Pratical Application of a Bridge Management System (J-BMS) in Japan", Civil Engineering Infrastructures Journal 48(1), pp.189-216.

Autelitano, F., Garilli, E., Giuliani, F. (2017) "Road route planning for transporting wind turbines in Europe", Proceedings of the AIIT International Congress on Transport 
Infrastructure and Systems TIS 2017, (G. Dell'Acqua, F. Wegman eds.), Taylor \& Francis Group, London.

Garilli, E., Autelitano, F., Giuliani, F., Guga, A., Maternini, G. (2017) “A reading key of motorization trend in Italy", Proceedings of the AIIT International Congress on Transport Infrastructure and Systems TIS 2017, (G. Dell'Acqua, F. Wegman eds.), Taylor \& Francis Group, London.

Calvi, G. M., Moratti, M., O’Reilly, G. J., Scattareggia, N., Monteiro, R., Malorno, D., Calvi, P.M., Pinho, R. (2019) "Once upon a Time in Italy: The Tale of the Morandi Bridge”, Structural Engineering International, Volume 29, Issue 2. International Association for Bridge and structural Engineering, Taylor \& Francis Online.

Kun, S., Vogt, R., Leuenberger, O. "Rehabilitation of reinforced concrete gerber bridges", Proceedings of the Third Conference on Smart Monitoring, Assessment and Rehabilitation of Civil Structures, SMAR 2015, Antalya, 7-9 September 2015, Turkey.

Shi, X., Liu, Y., Mooney, M., Berry, M., Hubbard, B., Fay, L., Leonard, A.B. (2010) "Effect of chloride-based deicers on reinforced concrete structures", WSDOT Research Report WA-RD 741.1. Washington State Department of Transportation, USA.

Autelitano, F., Rinaldi, M., Giuliani, F. (2019) "Winter highway maintenance strategies: Are all the sodium chloride salts the same?", Construction and Building Materials, Volume 226, Elsevier. 